\title{
An occult Follicular Thyroid Carcinoma revealed by an Isolated Caudaequina syndrome: a Rare Presentation
}

\author{
Chafiki Z*, Merzouki B, Hasnaoui J, Rouadi S, Abada R, Roubal M and Mahtar M \\ Department of ENT; 20 Août hospital, Ibn Rochd University Hospital, Morocco
}

Submission: December 19, 2016; Published: January 02, 2017

*Corresponding author: Chafiki Zakaria, Hopital 20 Aout, ENT Service, CHU Ibn Rushd, Casablanca, Morocco, Email : zakaria.chafiki@gmail.com

\section{Abstract}

Background: Follicular thyroid cancer (FTC) is a well-differentiated thyroid cancer that accounts for $15-20 \%$ of all Thyroid cancers. It is more likely to manifest as a distant metastasis than PTC as it tends to spread hematogenously with bones being the second most common site of metastasis after lungs.We report an unusual case of an occult FTC revealed by caudaequinasyndrome secondary to spinal metastasis as a first clinical manifestation of the disease.

Results: An 81 year old female presented to neurosurgery clinic with paraplegia and sphincteric dysfunction.Dorso-lumbo-sacral CT and MR imagingshowed an ill-limited expansilelytic tissue processinvolving L4, L5 and S1 vertebrae,extendinginto spinal canal with an invasion of caudaequina nerves. Biopsy'sresults wereconsistent with spinal metastasis of FTC.The patient was referred to the ENT department where a total thyroidectomy was carried out, and the primary tumor pathology was consistent with FTC.

Conclusion: Caudaequinasyndrome secondary to spinal metastasis is very uncommon as an initial finding of FTC without any previous symptoms of malignancy.Early diagnosis and prompt management of the primary carcinoma and the metastatic lesion may extend long-term survival and allow a favorable prognosis. Thyroidectomy with radioactive iodine ablation increases the 10-year survival in patients with metastatic disease.

Keywords: Follicular thyroid cancer; spinal metastasis; CaudaequinasyndromeThyroidectomy; radioactive iodine ablation

Abbreviations: FTC: Follicular Thyroid Cancer; DTC: Differentiated Thyroid Cancer; PTC: Papillary Thyroid Cancer; RAI: Radioactive Iodine Therapy; RT: Radiation Therapy

\section{Introduction}

Thyroid cancer is rare and accounts for roughly $1 \%$ of all new malignant disease with a male to female ratio of $1: 3$ [1]. Follicular thyroid cancer (FTC) is a well-differentiated thyroid cancer that accounts for $15-20 \%$ of cases $[2,3]$. Thyroid cancer initially presents with clinical symptoms due to metastatic lesions in less than $5 \%$ of cases [1]. FTC metastasizes to bone in $2-13 \%$ of patients with the spine being the most common bony metastatic site [4]. Spinal metastases most commonly involve the vertebral body and can lead to pathologic compression fractures and instability [5]. Caudaequina syndrome due to a spinal metastasis as a first presentation is extremely rare. We report an unusual case of an occult FTC revealed while a workup of caudaequinasyndrome was carried out to find out the lesion in question.

\section{Case Presentation}

An 81 year old female with no remarkable medical history, was referred to the ENT consultation for total thyroidectomy. Her medical history goes back to 1 year ago with a chronic lumbar pain recalcitrant to pain killers. The course was marked by the onset of weakness and heaviness of both legs along with gradual difficulties on walking for the last 5 months. A total functional impotence of the lower limbs was established 2 months after with constipation and urinary retention. This symptomatology prompted the patient to consult in Neurosurgeryclinic. Physical examination found paraplegia, numbness, tingling of saddle region andboth legs, and distal hypoesthesia. Due to the neurological status, an urgentdorso-lumbar CT scan was performed, revealing an ill-limited $(65 \times 74 \mathrm{~mm})$ lytic tissue 


\section{Global Journal of Otolaryngology}

process centered on the last 3 lumbar vertebrae, extending into spinal cannel, homogeneously enhanced aftercontrast material injection, extended over $81 \mathrm{~mm}$ in height (Figures 1 \& 2).

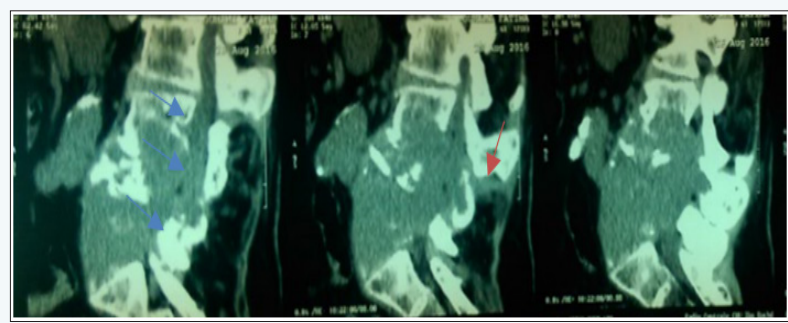

Figure 1: Dorso-lumbar CT scan -sagittal images-revealing an ill-limited lytic tissue process centered on the last 3 lumbarvertebrae (blue arrows),extending into spinal cannel (red arrow), measuring approximately $65 \times 74 \mathrm{~mm}$, extended over $81 \mathrm{~mm}$ in height.

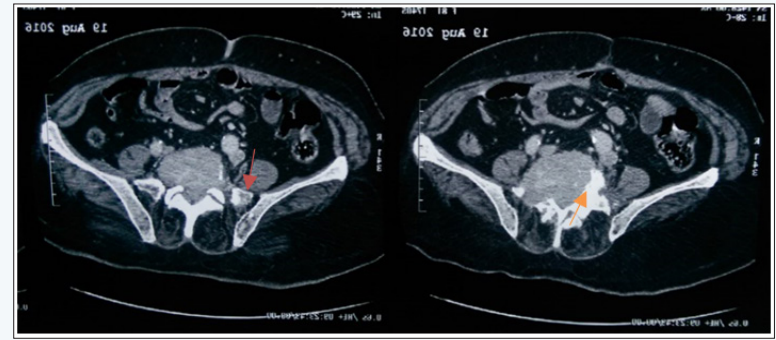

Figure 2: Dorso-lumbar CT scan -axial images-revealing an illdefined lytic tissue extending into spinal cannel (red arrow), and to paravertebral soft tissues (green arrow).

Lombo-sacral MRI showed a 90x52×77mm advanced lesion process, involving L4, L5 and S1 vertebrae, causing a cuneiform compression of L5, with a broad pre and paravertebral soft tissue invasion most importantly of the posterior arches of L4, L5 and S1 vertebrae, extension into spinal canal with an invasion of the roots of caudaequina nerves and infiltration of sacred holes with a corporal metastasis of L3 (Figures 3-5). A US-guided percutaneous Tru-cut biopsy of the tumor was performed. The histopathological examination revealed thyroid follicles filled with colloid material. The follicle cells were generally cuboid and round-oval shaped with hyperchromatic nuclei showing mild pleomorphism which was consistent with metastatic FTC.

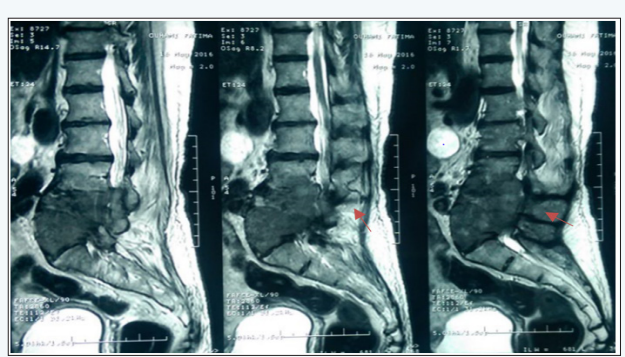

Figure 3: Lombo-sacral MRI - T2-weighted sagittal images revealing an approximately $90 \times 52 \times 77 \mathrm{~mm}$ expansile lesion process, involving L4, L5 and S1 vertebrae, with a cuneiform compression of L5 and extension into spinal canal (red arrow), with an invasion of the roots of caudaequina nerves and infiltration of sacred holes.

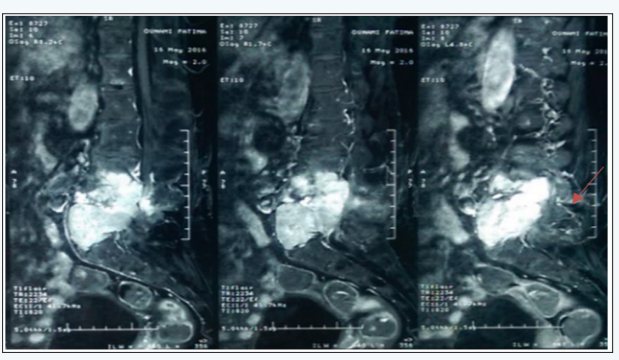

Figure 4: Dorso-lombo-sacral MRI -T1-weighted sagittal images with gadolinium - tumor mass centeredin L4, L5 and S1 vertebrae heterogeneously enhanced after injection of gadolinium, with a broad pre and paravertebral soft tissue invasion most importantly of the posterior arches ofL4, L5 and S1 vertebrae (red arrow).

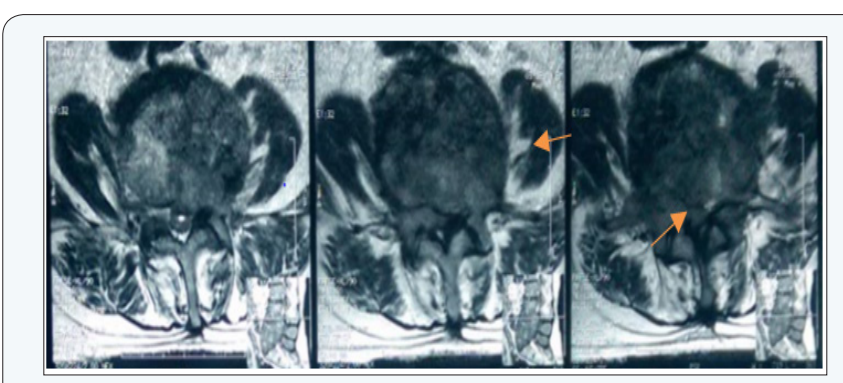

Figure 5: Lombo-sacral MRI -T1-weighted sagittal images - tumor mass with a broad pre and paravertebral soft tissue invasion most importantly of the left and posterior areas (green arrow).

Regarding these results, the patient was referred to the ENT department where a Thyroid US was considered, which demonstrated a small spongiform 9x8x4xmm TI-RADS- 2 nodule in the right lobe of the thyroid gland, and awell limited with a calcified wall, $12 \times 12 \times 9 \mathrm{~mm}$, TI-RADS-4A left basi-lobar nodule, avascular on doppler examination. Total thyroidectomy was performed, and the primary tumor pathology was reported to be FTC. Thyroid function tests were within the normal limits. Staging including chest and abdominopelvic CT was performed with no evidence of others distant metastases. The patient was then put on radioiodine therapy pending a neurosurgical management.

\section{Discussion}

Thyroid cancer is a rare entity that accounts for roughly $1 \%$ of all new malignant disease with a male to female ratio of 1:3 [1] broadly divided into two categories. Differentiated thyroid cancer (DTC) accounts for most malignancies $90 \%$ of all thyroid cancers. DTC is also categorized into papillary thyroid cancer (PTC) which represents $70-75 \%$ of all cases, where follicular thyroid cancer (FTC) is only seen in $15-20 \%$ of cases. Undifferentiated carcinomas, represented by anaplastic cancers which account for $<5 \%$ of thyroid cancers. Medullary carcinoma of the thyroid accounts for $5-10 \%[2,3]$.

Distant metastasis of thyroid cancer is well known, although it is present in only approximately $9 \%$ of patients with DTC 
[6]. FTC is more likely to manifest as a distant metastasis than PTC as it tends to spread hematogenously with bones being the second most common site of metastasis after lungs [7] and the spine being the most common bony metastatic site [4]. Distant bone metastasis of DTC usually occurs at the late stage of the disease with a higher incidence ranging from 7 to $20 \%$ in FTC comparing to PTC, which has an incidence of spinal metastasis of 1-7\% [8]. Spinal metastases from FTC most commonly involve the vertebral body and can lead to pathologic compression fractures and instability [5]. The involvement of pelvis, sternum, long bones, and ribs is also described [9].

FTC presents as a solitary thyroid nodule, such localized cases are associated with favorable outcomes, with an 80-95\% overall 10-year relative survival. However, the 10 -year survival rate diminishes to about $40 \%$ when distant metastasis is present [10]. Caudaequina syndrome secondary to spinal metastasis is a rare manifestation of the disease, and is a late-stage finding of thyroid carcinoma. It is very uncommon as an initial finding without any previous symptoms of malignancy. Only a few cases of this latter have been reported as the initial manifestation of FTC in the literature [11].

Early diagnosis of metastatic spinal disease is important because functional outcome depends on neurologic status at the time of presentation and also allows the research for the primarytumor and subsequently a correct and rapid management of the whole condition. Proye et al. [12] demonstrated that follicular carcinoma is usually less life threatening, and that early diagnosis and appropriate treatment for distant metastases can significantly prolong the life span and improve life quality. Shaha et al. [7] also reported that total thyroidectomy followed by radioactive iodine therapy (RAI) and thyroxine suppressive treatment extended long-term survival (10-15 years) in 44\% of patients with metastatic follicular thyroid carcinoma.

Treatment modalities available for metastatic spine tumors include radiation therapy (RT), surgery, and chemotherapy. The appropriate treatment for an individual patient requires a multidisciplinary approach. The case we present here is unique as the patient's first clinical manifestation was a paraplegia, and it was caused by a spinal metastasis with caudaequina nerves compression from an undiagnosed follicular thyroid cancer which makes thyroid carcinoma a differential diagnosis of every patient with neurological compression signs.

\section{Conclusion}

Through this case report, we wanted to emphasize that thyroid cancer is a possibility in the differential diagnosis in patient presenting with compressive neurological signs from a spinal mass lesion detected on imaging findings. Early diagnosis with a thorough assessment of thyroid gland when a spinal metastasis is suspected and prompt management of the primary carcinoma and the metastatic lesion, sustainable maintenance of thyroid suppression, and consideration of the patient's age, response to therapies, and comorbidities, may extend long-term survival and allow a favorable prognosis. Thyroidectomy with radioactive iodine ablation increases the 10 -year survival in patients with metastatic disease [1].

\section{References}

1. Gentian Toshkezi, Michael Galgano, Silva Libohova, Satya Marawar (2015) Isolated Spinal Metastasis with Spinal Cord Compression Leads to a Diagnosis of a Follicular Thyroid Carcinoma. AANS 7(10): 346.

2. Wilson PC, Millar BM, Brierley JD (2004) The management of advanced thyroid cancer. Clinical Oncology 16(8): 561-568.

3. Sciubba DM, Petteys RJ, Kang S, Than KD, Gokaslan ZL, et al. (2010) Solitary spinal metastasis of Hürthle cell thyroid carcinoma. J Clin Neurosci 17(6): 797-801.

4. Kushchayeva YS, Kushchayev SV, Wexler JA, Carroll NM, Preul MC, et al. (2014) Current treatment modalities for spinal metastases secondary to thyroid carcinoma. Thyroid 24(10): 1443-1455.

5. Ramadan S, Ugas MA, Berwick RJ, Notay M, Cho H, et al. (2012) Spinal metastasis in thyroid cancer. Head Neck Oncol 4: 39.

6. Ruegemer JJ, Hay ID, Bergstralh EJ, Ryan JJ, Offord KP, et al. (1988) Distant metastases in differentiated thyroid carcinoma: a multivariate analysis of prognostic variables. J Clin Endocrinol Metab 67(3): 501508.

7. Shaha AR, Ferlito A, Rinaldo A (2001) Distant metastasesfrom thyroid and parathyroid cancer. ORL J Otorhinolaryngol Relat Spec 63(4): 243249.

8. Wexler JA (2011) Approach to the thyroid cancer patient with bone metastases. J Clin Endocrinol Metab 96(8): 2296-2307.

9. Michael F McNeeley, Annette Sabath, Ken F Linnau (2012) Follicular thyroid carcinoma presenting as acute cord compression due to thoracic vertebral metastasis. Radiology Case Reports 7(3): 687.

10. Eustatia-Rutten C, Romijn J, Guijt M, Vielvoye G, Van den Berg R, et al. (2003) Outcome of palliative embolization of bone metastases in differentiated thyroid carcinoma. J Clin Endocrinol Metab 88(7): 31843189.

11. Akhtar S, Adeel M (2016) An Unusual Case of CaudaEquina Secondary to Spinal Metastasis of Thyroid Cancer. Iran J Otorhinolaryngol 28(84): 67-71.

12. Proye CA, Dromer DH, Carnaille BM, Gontier AJ, Goropoulos A, et al. (1992) Is it still worthwhile to treat bone metastases from differentiated thyroidcarcinoma with radioactive iodine? World J Surg 16(4): 640-645. 
Your next submission with JuniperPublishers will reach you the below assets

- Quality Editorial service

- Swift Peer Review

- Reprints availability

- E-prints Service

- Manuscript Podcast for convenient understanding

- Global attainment for your research

- Manuscript accessibility in different formats ( Pdf, E-pub, Full Text, Audio)

- Unceasing customer service

Track the below URL for one-step submission https://juniperpublishers.com/online-submission.php 